\title{
GDC ANNOUNCES ARF DECREASE FOR DCPS
}

The GDC has announced that it is increasing its annual retention fee (ARF) from $£ 576$ to $£ 890$ for dentists and decreasing the fee for dental care professionals (DCPs) from $£ 120$ to $£ 116$. In June, the GDC proposed that the fee for dentists would increase to $£ 945$, and that the fee for DCPs would increase to $£ 128$.

The British Association of Dental Nurses (BADN) welcomed the GDC's decision to set a lower ARF of $£ 116$ for dental nurses, but says that the fee is still too high in comparison to dental nurse salaries, especially for those who work part time.

The BADN strongly believes that the ARF for dental nurses should be considerably lower than that for hygienists and therapists, and that there should be a reduced ARF for all registrants who work part time.

The British Dental Association (BDA), who has opposed the ARF increase for dentists since it was proposed in June, was granted a judicial review of the GDC's ARF consultation. If the $\mathrm{BDA}$ are successful, the Regulations implementing the ARF increase for dentists are likely to be quashed. The review was due to take place on 15 December 2014 in the High Court and the result will be reported in the next issue of BDJ Team.

The new fees must be paid by dentists by 31 December 2014 and by DCPs by 31 July 2015.

\section{DO YOU KNOW AN OUTSTANDING DENTAL NURSE?}

The British Association of Dental Nurses (BADN) are requesting nominations for their 2015 Outstanding Contribution to Dental Nursing (OCDN) Award. The award will be presented in May 2015 at the Honours and Awards Dinner at the British Dental Conference and Exhibition in Manchester.

To nominate someone for the award, first read the 2015 OCDN nomination guidelines, which can be accessed via the BADN website: http://badn.org.uk/wp-content/ uploads/2014/11/BADN-2015-OCDN-GUIDELINES.pdf.

Nominations must be made on the 2015 OCDN Application Form and received by BADN by close of business on 13 February 2015: http://badn.org.uk/wp-content/uploads/2014/11/ BADN-2015-OCDN-GUIDELINES.pdf.

\section{DO YOU WANT TO BE A DENTAL HYPNOTIST?}

Often the images that first come to mind when hypnosis is mentioned is one of entertainment, counting backwards and audience members doing silly things much to the amusement of the audience. However, did you know it can be applied and used in a dental setting? Some of the earliest accounts of hypnosis being used in a dental practice were in Paris in 1836 when a physician performed an extraction on a patient who was hypnotised.

Today, dental professionals use it in practice to provide many significant benefits for both patient and practice. It can be used to help treat patients with all levels of anxiety and alleviate discomfort and pain during treatment. Recently there have been cases where hypnosis has actually replaced the use of anaesthetic.

Hypnosis can be used by all team members, especially those who work chairside, to bring about a more relaxed state in patients. It can also help reduce and normalise their fear of the dentist and of treatment making patients happier and calmer and more likely to return to the practice.

Sounds like something you would like to try? Then why not come along to the British Dental Association's (BDA's) one day interactive workshop on Friday 30 January 2015 in London led by expert trainer and qualified psychotherapist and hypnotherapist Anthony Asquith?

To find out more about this course please visit www.bda.org/training for full details and learning objectives.

To book your place at this event call the BDA Events team today on 02075634590 .

NEW CHAIR OF THE BOARD OF NEBDN

Dental nurse training manager Marie

Parker (pictured, right) has been

appointed chair of the board of the

National Examining Board for Dental

Nurses (NEBDN).

Marie, who works at King's College

Hospital in London, takes over the role

from John Darby (pictured, left), Associate

I Dean of the Dental Department at Health

Education Kent Surrey and Sussex. Lindsay

I Mitchell, who has many years' experience

I in educational research and development,

has been appointed deputy chair.

Marie qualified as a dental nurse in 1994 and has worked in various areas of dentistry. She has been a dental nurse trainer since 2000 and has examined for NEBDN since 2001. Marie gained

her master's degree in education in 2009 and has developed and delivered a variety of courses and qualifications for the dental team.

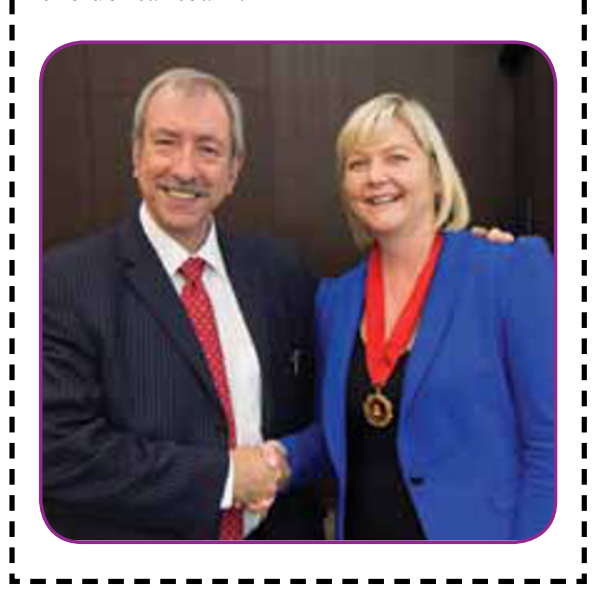

\section{NEW GUIDELINE TO IMPROVE COMMUNITIES' ORAL HEALTH}

NICE published a new guideline in October calling on local authorities to improve the oral health of their communities through better advice and support in oral hygiene.

The guideline states that local authorities should consider supervised toothbrushing and fluoride varnishing schemes for areas where children are at high risk of poor oral health.

The full guideline can be viewed at http:// www.nice.org.uk/guidance/ph55.

Do you have a news story that you would like included in BDJ Team? Send your press release or a summary of your story to the Editor at bdjteam@nature.com. 